\title{
In vitro assay for human thyroid hormone receptor $\beta$ agonist and antagonist effects of individual polychlorinated naphthalenes and Halowax mixtures
}

\author{
LI Na $^{1}$, MA Mei $^{1}$, WANG ZiJian ${ }^{1 *} \&$ SENTHIL KUMARAN Satyanarayanan ${ }^{2}$ \\ ${ }^{1}$ State Key Laboratory of Environmental Aquatic Chemistry, Research Center for Eco-Environmental Sciences, Chinese Academy of Sciences, \\ Beijing 100085, China; \\ ${ }^{2}$ Unit of Toxicology, Bharathiar University, Coimbatore 641046, India
}

Received April 15, 2010; accepted August 3, 2010

\begin{abstract}
Polychlorinated naphthalenes (PCNs) are dioxin-like environmental contaminants. There is growing concern over the endocrine-disrupting effects of PCNs, but very few studies have investigated the effect of PCNs on the thyroid system. This study used a yeast two-hybrid assay, which included the recombinant human thyroid receptor(TR)- $\beta$ and reporter genes, to characterize the TR $\beta$-disrupting effects of five individual PCN congeners, five PCN Halowax mixtures, and naphthalene. Their agonist and antagonist effects were studied in the absence and presence of $5 \times 10^{-7} \mathrm{~mol} / \mathrm{L} 3,3^{\prime}, 5$-triiodo-L-thyronine, which induced submaximal $\beta$-galactosidase activity. Naphthalene, 1,2,3,4,5,6,7,8-octachloronaphthalene and all of the Halowax mixtures (Halowax 1000, $1001,1013,1014$ and 1099) showed no agonist or antagonist activity on TR $\beta$ at the concentrations tested (up to $10^{-2} \mathrm{~g} / \mathrm{L}$ ). The lighter PCN congeners, namely 1-chloronaphthalene, 2-chloronaphthalene, 1,4-dichloronaphthalene and 1,2,3,4-tetrachloronaphthalene showed no agonist activity but showed significant antagonist activity on TR $\beta$. The $20 \%$ relative inhibitory concentrations of these PCNs were less than $9.13 \times 10^{-3} \mathrm{~g} / \mathrm{L}$. Thus, bioaccumulation of these lighter PCN congeners may disrupt the thyroid hormone system and inhibit TR-mediated cellular responses. Studies in the future should investigate the possible associations between the presence PCNs and adverse health outcomes.
\end{abstract}

in vitro bioassay, thyroid hormone receptors, polychlorinated naphthalenes, yeast two-hybrid assay

Citation: $\quad \mathrm{Li} \mathrm{N}, \mathrm{Ma} \mathrm{M}$, Wang Z J, et al. In vitro assay for human thyroid hormone receptor $\beta$ agonist and antagonist effects of individual polychlorinated naphthalenes and Halowax mixtures. Chinese Sci Bull, 2011, 56: 508-513, doi: 10.1007/s11434-010-4315-9

Concern over the effects of environmental chemicals on wildlife and humans via changes in endocrine systems has greatly increased over the last few decades [1]. Environmental estrogens have been the focus of the majority of studies in for over 20 years [2,3]. However, in recent years, the effects of synthetic chemicals on the thyroid system have received increasing attention because abundant evidence from in vivo and in vitro studies has demonstrated that the thyroid system is particularly vulnerable to endocrine-disrupting effects [4].

Normal levels of thyroid hormones are essential for ap-

*Corresponding author (email: wangzj@ rcees.ac.cn) propriate growth and development in fetal life and childhood. Changes in thyroid hormone levels can adversely affect fertility and postnatal development in humans and animals [5]. Many environmental chemicals have been found to influence thyroid function, including polychlorinated biphenyls (PCBs), dioxins, polybrominated diphenylethers (PBDEs), polybrominated biphenyls (PBBs), phenols and phthalates [4]. In particular, the polyhalogenated aromatic hydrocarbons (PHAHs), such as PCBs, PBDEs and PBBs, have attracted much attention because of their ability to disrupt thyroid function due to their environmental persistence and lipophilicity. For example, PCBs can decrease the levels of circulating thyroid hormones [6] and BDE209 was 
found to disrupt thyroid receptors (TRs) in vitro using the T-Screen method [7]. Meanwhile, in rodent studies, PBDEs reduced the circulating levels of thyroid hormones and showed an even closer structural relationship to 3,3',5,5'tetraiodo-L-thyronine $\left(\mathrm{T}_{4}\right)$ than PCBs [8].

Polychlorinated naphthalenes (PCNs) are a group of industrial chemicals belonging to the PHAH family, and consist of naphthalene substituted with 1-8 chlorine atoms [9]. PCNs are structurally similar to PCBs and they exhibit similar physical and chemical properties to PCBs [9]. PCNs are used as wood preservatives, for cable insulation, electroplating masking compounds, and in dye production [10]. The production and use of PCNs were banned in Europe and in the United States in the 1980s because of their toxicity and environmental persistence [11]. However, the global production of PCNs is estimated at about 150000 metric tons [12]. PCNs are still being released to the environment as contaminants of other industrial mixtures and as byproducts of solid waste combustion [13], while illegal importation of PCN-containing products into Japan has been reported after 2000 [14]. It is clear that PCNs are widespread pollutants and, with recent developments in analytical methods and increased availability of standards, they have been detected in air, water, sediment and biota [15]. PCNs are highly hydrophobic, semi-volatile, thermally stable, and low flammability, and they are detected in particularly high levels in aquatic organisms, posing a severe threat to the environment [15]. Recently, PCNs were defined as persistent organic pollutants in the Convention on Long-Range Transboundary Air Pollution by the United Nations Economic Commission for Europe [16]. However, the toxic responses associated with PCNs were mostly studied in terms of aryl hydrocarbon receptor-dependent mechanisms of action $[17,18]$, but their toxicity may also be mediated via other independent mechanisms. To date, very few studies have evaluated the disruptive activity of PCNs on thyroid function, which is known to be vulnerable to PHAHs. Therefore, there is an urgent need to evaluate these effects of PCNs.
The direct effects of chemicals on thyroid hormone receptors appear to be more important and sensitive endpoints than simply analyzing circulating hormone levels, thyroid size or histopathology, because most of the bioactivity of steroid hormones is mediated through their receptors to regulate the transcription of target genes in ligand-depend ent manners [19,20]. In our previous study [21], we developed a yeast two-hybrid system to screen chemicals with agonist or antagonist activity on TR $\beta$ and found that many chemicals, including PCBs, PBDEs, PBBs, flame retardants, phthalates, pesticides and phenols target the TR $\beta$. The yeast cells were co-transformed with human TR $\beta$ and a coactivator of human TR $\beta$ (GRIP1); therefore, this system overcomes the differences in transcriptional activation of yeast and vertebrates [22]. The aim of the present study was to determine whether PCNs have the capacity to disrupt TR $\beta$. For in vitro screening, we tested five Halowax mixtures (Koppers Company, Pittsburgh, PA, USA), which are typical PCN formulations, and five other PCNs using this yeast two-hybrid assay.

\section{Materials and methods}

\subsection{Chemicals}

Dimethyl sulfoxide (DMSO, 99.5\%), 3,3',5-triiodo-L-thyronine $\left(\mathrm{T}_{3}, 95 \%\right)$ and $3,3^{\prime}, 5,5^{\prime}$-tetraiodo-L-thyronine $\left(\mathrm{T}_{4}\right.$, 95\%) were purchased from Sigma Chemicals (St. Louis, MO, USA). All of the PCNs (Table 1) were obtained from AccuStandard (New Haven, CT, USA). Amiodarone hydrochloride $(\mathrm{AH},>95 \%)$ was purchased from Shanghai Pharmaceuticals Co. (Shanghai, China). Stock solutions of all compounds were prepared in DMSO.

\section{$1.2 \beta$-Galactosidase assay}

All bioassays, including the agonist and antagonist activity tests, were conducted using the yeast strain hTR $\beta$-GRIP1,

Table 1 Chemicals tested in this study

\begin{tabular}{|c|c|c|c|c|}
\hline Chemicals & Abbreviation & Supplier & CAS no. & Purity \\
\hline Naphthalene & Naphthalene & Accustandard & $91-20-3$ & $99.80 \%$ \\
\hline 1-Chloronaphthalene & $1-\mathrm{CN}$ & Accustandard & $90-13-1$ & $100 \%$ \\
\hline 2-Chloronaphthalene & $2-\mathrm{CN}$ & Accustandard & $91-58-7$ & $98.50 \%$ \\
\hline 1,4-Dichloronaphthalene & 1,4-DiCN & Accustandard & $1825-31-6$ & $99.40 \%$ \\
\hline 1,2,3,4-Tetrachloronaphthalene & $1,2,3,4-\mathrm{TeCN}$ & Accustandard & $20020-02-4$ & $100 \%$ \\
\hline $1,2,3,4,5,6,7,8$-Octachloronaphthalene & $\mathrm{OCN}$ & Accustandard & $2234-13-1$ & $98.30 \%$ \\
\hline Halowax 1000 mono-diCN $(26 \% \mathrm{Cl})$ & Halowax 1000 & Accustandard & $58718-66-4$ & Tech Mix \\
\hline Halowax 1001 di-penta $(50 \% \mathrm{Cl})$ & Halowax 1001 & Accustandard & $58718-67-5$ & Tech Mix \\
\hline Halowax 1013 tri-pentaCN $(56 \% \mathrm{Cl})$ & Halowax 1013 & Accustandard & $1321-64-8$ & Tech Mix \\
\hline Halowax 1014 tetra-hexaCN $(62 \% \mathrm{Cl})$ & Halowax 1014 & Accustandard & $1335-87-1$ & Tech Mix \\
\hline Halowax 1099 di-pentaCN (52\% Cl) & Halowax 1099 & Accustandard & $39450-05-0$ & Tech Mix \\
\hline
\end{tabular}


as described previously [21]. All assays were conducted in at least triplicate. Exponentially growing overnight cultures were diluted with synthetic dropout nutrient medium lacking tryptophan and leucine (SD/-Trp-Leu) to an optical density $(A)$ at $600 \mathrm{~nm}$ of 0.75 . Each test chemical was serially diluted in DMSO to generate 6-8 concentrations. Five microliters of each dilution was combined with $995 \mu \mathrm{L}$ of medium containing $5 \times 10^{3}$ yeast cells $/ \mathrm{mL}$, resulting in a test culture in which the volume of DMSO did not exceed $1.0 \%$ of the total volume (1.0\% DMSO has no toxicity on this system). Each assay group included a positive control $\left(\mathrm{T}_{3}\right)$ and a negative control (DMSO). To determine agonist activity, the PCNs were tested in the absence of $\mathrm{T}_{3}$. Antagonist activity was determined in the presence of $5 \times 10^{-7}$ $\mathrm{mol} / \mathrm{L}$ of $\mathrm{T}_{3}$, a concentration that produces a submaximal stimulatory response [23].

Test cultures $(200 \mu \mathrm{L})$ were transferred to each well of a 96-well plate and incubated at $30^{\circ} \mathrm{C}$ with vigorous orbital shaking $(300 \times g)$ on a titer plate shaker (Heidolph TITRAMAX 1000, Germany) for $2 \mathrm{~h}$. The cell density of the culture was then measured at a wavelength of $600 \mathrm{~nm}$ (TECAN GENios A-5002, Austria). Next, $50 \mu \mathrm{L}$ of the test culture was transferred to a new 96-well plate and followed by the addition of $120 \mu \mathrm{L}$ of of Z-buffer $(16.1 \mathrm{~g} / \mathrm{L}$ $\mathrm{Na}_{2} \mathrm{HPO}_{4} \cdot 7 \mathrm{H}_{2} \mathrm{O} ; 5.5 \mathrm{~g} / \mathrm{L} \quad \mathrm{NaH}_{2} \mathrm{PO}_{4} \cdot \mathrm{H}_{2} \mathrm{O} ; 0.75 \mathrm{~g} / \mathrm{L} \mathrm{KCl}$; $0.246 \mathrm{~g} / \mathrm{L} \mathrm{MgSO}_{4} \cdot 7 \mathrm{H}_{2} \mathrm{O}$ ) and $20 \mu \mathrm{L}$ of chloroform. The samples were carefully mixed (vortex $25 \mathrm{~s}$ ) and preincubated for $5 \mathrm{~min}$ at $30^{\circ} \mathrm{C}$. The enzyme reaction was started by adding $40 \mu \mathrm{L}$ of $o$-nitrophenyl- $\beta$-D-galactopyranoside $\left(13.3 \mathrm{mmol} / \mathrm{L}\right.$, dissolved in Z-buffer) and incubated at $30^{\circ} \mathrm{C}$ on the titer plate shaker for $60 \mathrm{~min}$. The reactions were terminated by adding $100 \mu \mathrm{L}$ of $\mathrm{Na}_{2} \mathrm{CO}_{3}(1 \mathrm{~mol} / \mathrm{L})$. After centrifugation at $12000 \times \mathrm{g}$ for $15 \mathrm{~min}$ (Sigma Laborzentrifugen $2 \mathrm{~K} 15$, Germany), $200 \mu \mathrm{L}$ of the supernatant was transferred into a new 96-well plate and the $A_{420 \mathrm{~nm}}$ was determined (TECAN GENios A-5002, Austria).

The $\beta$-galactosidase activity was calculated using the equations $u=\mathrm{Cs} / t \cdot V \cdot D \cdot \mathrm{ODS}$ and $\mathrm{Cs}=10^{-6}(\mathrm{AS}-\mathrm{AB}) / \varepsilon d$, where $u=\beta$-galactosidase activity, $t=$ enzyme reaction incubation time, $V=$ volume of the test culture, $D=$ dilution factor, $\mathrm{ODS}=A_{600}$ of the test culture, $\mathrm{AS}=\mathrm{A}_{420}$ of the enzyme reaction supernatant of the sample, $\mathrm{AB}=\mathrm{A}_{420}$ of the enzyme reaction supernatant of the blank, $\varepsilon=\varepsilon$ for $o$-nitrophenol in the enzyme assay reaction mix, and $d=$ diameter of the cuvette [23].

To exclude false results caused by cytotoxicity of the yeast, the viability of the cells was determined spectrophotometrically as a change of cell density $\left(\mathrm{A}_{600 \mathrm{~nm}}\right)$ of the assay medium, as previously described (Table 2) [21].

\subsection{Data analysis}

The 20\% relative effective concentration (REC20) of each compound (inducing 20\% of the maximum effect) and/or
Table 2 Two-hybrid TR bioassay used to determine the possible endocrine disrupting potency ${ }^{\text {a) }}$

\begin{tabular}{ccc}
\hline Reference material & Endpoint & REC50 or RIC50 $\left(\mathrm{mol} \mathrm{L}^{-1}\right)$ \\
\hline $\mathrm{T}_{3}$ & Agonistic activity of TR & $1.1 \times 10^{-7}$ \\
$\mathrm{~T}_{4}$ & Agonistic activity of TR & $2.7 \times 10^{-7}$ \\
$\mathrm{AH}$ & $\begin{array}{c}\text { Antagonistic activity of TR } \\
\text { in the presence of } \mathrm{T}_{3}\end{array}$ & $2.4 \times 10^{-7}$ \\
\hline
\end{tabular}

a) According to [21]. $\mathrm{TR}=$ thyroid receptor; $\mathrm{T}_{3}=3,3^{\prime}, 5$-triiodo-L-thyronine; $\mathrm{T}_{4}=3,3^{\prime}, 5,5^{\prime}$-tetraiodo-L-thyronine; $\mathrm{AH}=$ amiodarone hydrochloride; REC50 = concentration inducing $50 \%$ of the maximum effect; RIC50 $=$ concentration causing a 50\% inhibition of the maximum effect.

the $20 \%$ relative inhibitory concentration (RIC20) of each compound (reducing $20 \%$ of the maximum effect) were calculated from a dose-response curve generated using a four-parameter logistic model based on the MarquardtLevenberg algorithm (Sigmaplot 4.0, SPSS, Chicago, IL, USA) [24]. For data analysis, REC20 and RIC20 values were used to identify whether the tested chemicals had agonist or antagonist activities. If the magnitudes of the agonist or antagonist effects of the tested chemicals were less than $10 \%$, they were considered to have no effect on the TR at these concentrations.

\section{Results}

To determine the agonist activity of PCNs, the yeast strains were treated with varying concentrations of PCNs, and $\beta$-galactosidase activities were measured. We found that $\beta$-galactosidase activity was not induced by PCNs, even at the highest concentration of $1.0 \times 10^{-2} \mathrm{~g} / \mathrm{L}$. Therefore, none of the chemicals tested acted as TR agonists at the concentrations used here. The dose-response relationships are presented in Figure 1.

To determine the antagonist activity of PCNs, they were co-administered with $5 \times 10^{-7} \mathrm{~mol} / \mathrm{L}$ of $\mathrm{T}_{3}$, a concentration that induced submaximal $\beta$-galactosidase expression. This test revealed that some PCNs inhibited $\beta$-galactosidase activities in dose-dependent manners and that some of the PCNs were TR antagonists. In brief, Halowax 1000, Halowax 1001, Halowax 1013, Halowax 1014, Halowax 1099, naphthalene and OCN did not exhibit TR antagonist effects. By contrast, 1-chloronaphthalene (1-CN), 2-chloronaphthalene (2-CN), 1,4-dichloronaphthalene (1,4-DiCN) and 1,2,3,4tetrachloronaphthalene $(1,2,3,4-\mathrm{TeCN})$ were TR antagonists, acting in a dose-dependent manner (Figure 2). The RIC20s of 1-CN, 2-CN, 1,4-DiCN and 1,2,3,4-TeCN were $5.82 \times 10^{-3}, 9.13 \times 10^{-3}, 3.04 \times 10^{-3}$ and $2.47 \times 10^{-3} \mathrm{~g} / \mathrm{L}$, respectively (Table 3 ).

\section{Discussion}

In recent years, PCNs have been a focus of research using a 

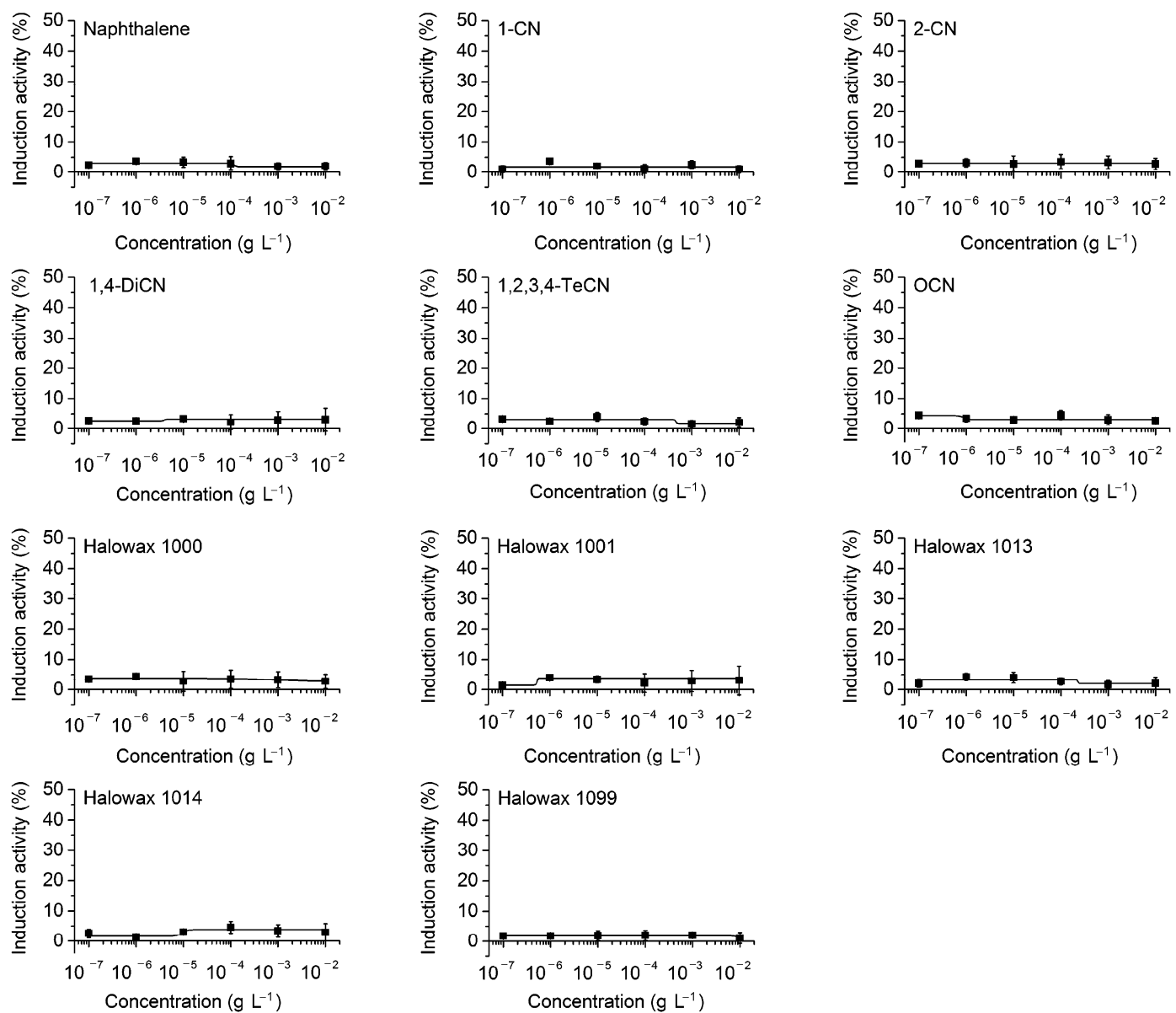

Figure 1 Dose-response activities of polychlorinated naphthalenes using the yeast strain hTR-GRIP1 system to determine their activity as agonists of the thyroid receptor (TR). The agonistic activity of each chemical is represented as the percent induction activity relative to the maximum induced by 3,3',5-triiodo-L-thyronine $\left(\mathrm{T}_{3}\right)$. Values are means \pm standard error $(n=3)$. OCN = 1,2,3,4,5,6,7,8-octachloronaphthalene; 1 -CN $=1$-chloronaphthalene; 2-CN = 2-chloronaphthalene; 1,4 - $\mathrm{DiCN}=1,4$-dichloronaphthalene; 1,2,3,4-TeCN = 1,2,3,4-tetrachloronaphthalene.

Table 3 Thyroid receptor (TR) agonistic and antagonistic potency of polychlorinated naphthalenes (PCNs) in the yeast strain hTR-GRIP1 assay ${ }^{\text {a) }}$

\begin{tabular}{ccc}
\hline Compounds & $\begin{array}{c}\text { TR agonistic activity } \\
\text { REC20 }\left(\mathrm{g} \mathrm{L}^{-1}\right)\end{array}$ & $\begin{array}{c}\text { TR antagonistic activity } \\
\text { RIC20 }\left(\mathrm{g} \mathrm{L}^{-1}\right)\end{array}$ \\
\hline Naphthalene & - & - \\
1-CN & - & $5.82 \times 10^{-3}$ \\
2-CN & - & $9.13 \times 10^{-3}$ \\
1,4-DiCN & - & $3.04 \times 10^{-3}$ \\
1,2,3,4-TeCN & - & $2.47 \times 10^{-3}$ \\
OCN & - & - \\
Halowax 1000 & - & - \\
Halowax 1001 & - & - \\
Halowax 1013 & - & - \\
Halowax 1014 & - & \\
Halowax 1099 & & - \\
\hline
\end{tabular}

a) Values are means \pm standard error $(n=3)$. REC20 = concentration inducing $20 \%$ of the maximum effect; RIC20 = concentration reducing the maximum effect by $20 \%$; OCN $=1,2,3,4,5,6,7,8$-octachloronaphthalene; 1-CN=1-chloronaphthalene; 2-CN=2-chloronaphthalene; 1,4-DiCN=1,4dichloronaphthalene; 1,2,3,4-TeCN = 1,2,3,4-tetrachloronaphthalene; - , no response. variety of analytical methods, to determine their levels in the food chain and human or animal exposure, and the presence in the Laurentian Great Lakes ecosystem [15,25-27]. However, to our knowledge, very few studies have examined the effects of PCNs on the thyroid hormone system.

In this study, we examined the thyroid-disrupting potencies of PCNs, and all of the PCNs tested here were ineffective as TR $\beta$ agonists. However, some of the PCNs acted as TR antagonists at low concentrations (RIC20 $<9.13 \times 10^{-3}$ $\mathrm{g} / \mathrm{L}$ ), and acted in dose-dependent manners. These results confirm those of our previous study using other PHAHs that PCBs, PBBs and PBDEs are not agonists for the TR $\beta$, but instead acted as antagonists at very low concentration (RIC20s $<5 \times 10^{-7} \mathrm{~g} / \mathrm{L}$ ) [21]. Similar results were reported by Schriks et al. [7] for other PHAHs, where it was found that BDE206 was an antagonist and did not respond in the $\mathrm{T}$-screen when tested in the absence of $\mathrm{T}_{3}$. PCNs were weaker TR antagonists than PCBs, PBBs and PBDEs, but had a similar antagonist activity as phenols, phthalate, pesticides and bisphenol A derivatives [21]. The finding that the PCNs tested in this study have considerable thyroid antagonist effects is 

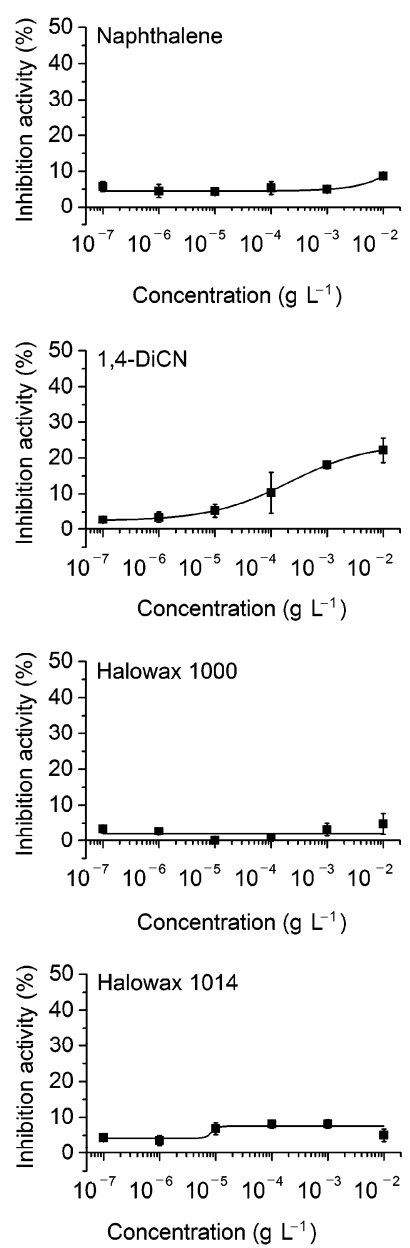
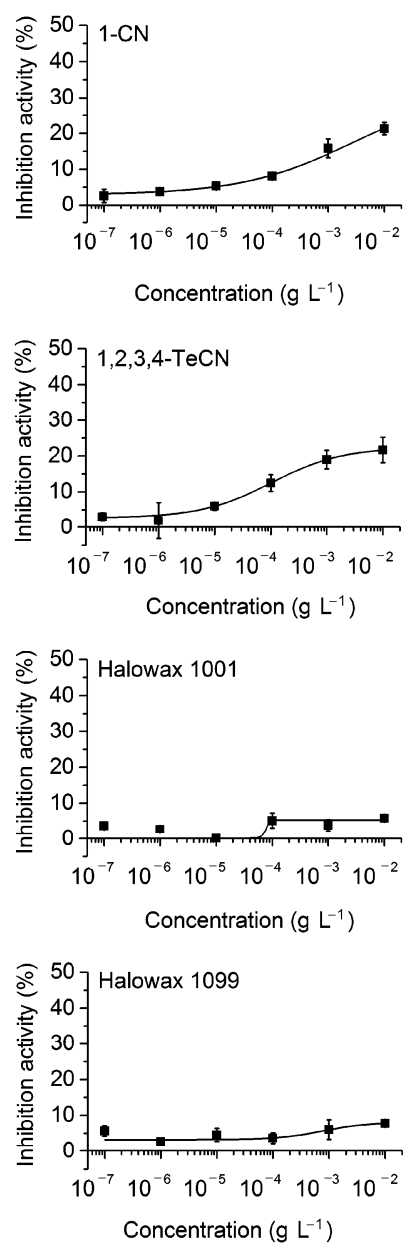
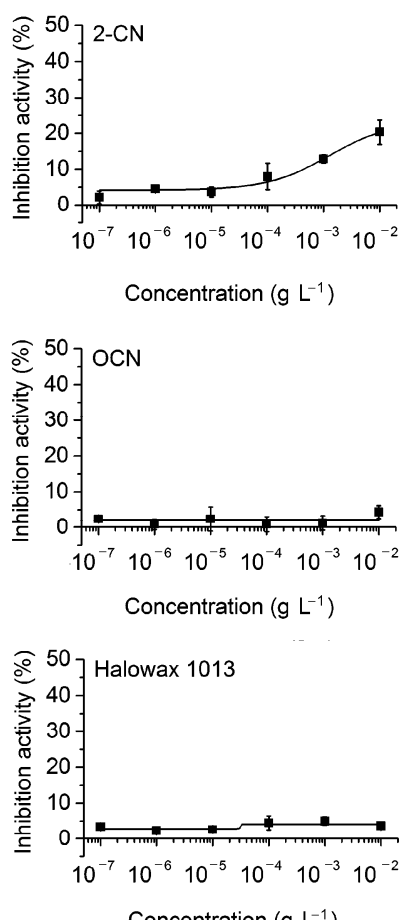

Concentration $\left(\mathrm{g} \mathrm{L}^{-1}\right)$

Figure 2 Dose-response activities of polychlorinated naphthalenes using the yeast strain hTR-GRIP1 system to determine their activity as antagonists for the thyroid receptor (TR). The antagonistic activity of each chemical is represented as the percent inhibition activity relative to the maximum induced by 3,3',5-triiodo-L-thyronine $\left(\mathrm{T}_{3}\right)$. Values are means \pm standard error $(n=3)$. OCN = 1,2,3,4,5,6,7,8-octachloronaphthalene; 1 -CN $=1$-chloronaphthalene; 2 -CN = 2-chloronaphthalene; 1,4 -DiCN = 1,4-dichloronaphthalene; 1,2,3,4-TeCN = 1,2,3,4-tetrachloronaphthalene.

particularly interesting.

The thyroid-disrupting potencies of individual PCN congeners differ compared with their relative dioxin-like activities.The dioxin-like activities of individual PCN congeners were found to be related to their chemical structures in terms of the number of chlorine molecules and the positions of these chlorine molecules. Monochlorinated, dichlorinated, trichlorinated and tetrachlorinated congeners were relatively inactive while pentachlorinated, hexachlorinated, and heptachlorinated congeners were the most potent [18]. In the present study, 1-CN, 2-CN, 1,4-DiCN and 1,2,3,4-TeCN exhibited similar potencies as TR $\beta$ antagonists, while OCN was not an antagonist for TR $\beta$ at the concentrations tested. This indicates that the lighter congeners show greater potential to disrupt the thyroid system, which is different from their dioxin-like activities. Of note, most of the PCNs present in air are the lighter congeners; trichlorinated and tetrachlorinated naphthalenes account for approximately $80 \%$ and $90-95 \%$ of the total PCN mass in ambient and arctic air, respectively, based on air sampling of PCNs in the United Kingdom, and it was concluded that air masses from the United Kingdom and Europe may be influencing PCN burdens more than PCBs [28,29]. Thus, the thyroid-disrupting effects of the lighter congeners may cause severe adverse effects in human acting via airborne exposure.

PCN mixtures are produced in several countries under the tradenames Halowax, Nibren, Clonaicre and Seekay waxes and Cerifal Materials, and are used worldwide, and persist in the environment causing long-term adverse effects [12]. In the present study, none of the Halowax compounds tested acted as agonists or antagonists of TR $\beta$. Some reports have demonstrated the toxicity of Halowax mixtures. For example, Halowax 1014 was reported to induce hepatic ethoxyresorufin- $O$-deethylase (EROD) activity in rainbow trout [30], while Halowaxes 1014 and 1013 were reported to be toxic to medaka (Oryzias latipes) during early life [18]. From the results in the present study, we may speculate that only a few PCNs contained in Halowax mixtures can disrupt TR $\beta$ or that the concentrations of PCNs that act as agonists or antagonists for TR $\beta$ are very low in Halowax mix- 
tures.

In the present study, the RIC20s of these PCNs ranged from $2.47 \times 10^{-3} \mathrm{~g} / \mathrm{L}$ to $9.13 \times 10^{-3} \mathrm{~g} / \mathrm{L}$. Because these molecules readily bioaccumulate within the food chain [26] and $\mathrm{T}_{3}$ and $\mathrm{T}_{4}$ are always present in vivo $\left(\mathrm{T}_{3}: 13.9-26.4 \mathrm{nmol}\right.$; $\mathrm{T}_{4}$ : 80-103 nmol) [31], PCNs may act as antagonists in human and animals if their accumulation within the body reaches a threshold level. Thus, PCNs must receive greater attention and more comprehensive studies, including in vivo tests, are needed to collect more information for adequate risk assessment. If PCNs combine with other thyroid-disrupting chemicals such as phenols, phthalate, parabens and pesticides, their adverse effects in humans may escalate. Therefore, future studies should evaluate the possible link between the presence of additional PCNs and biological health.

This study was supported by the National Basic Research Program of China (2009CB421605) and the National Natural Science Foundation of China (20877089 and 20737003).

1 Sonnenschein C, Soto A M. An updated review of environmental estrogen and androgen mimics and antagonists. J Steroid Biochem Mol Biol, 1998, 65: 143-150

2 Miller D, Wheals B B, Beresford N, et al. Estrogenic activity of phenolic additives determined by an in vitro yeast bioassay. Environ Health Perspect, 2001, 109: 133-138

3 Takeyoshi M, Yamasaki K, Sawaki M, et al. The efficacy of endocrine disruptor screening tests in detecting anti-estrogenic effects downstream of receptor-ligand interactions. Toxicol Lett, 2002, 126: 91-98

4 Boas M, Feldt-Rasmussen U, Skakkebaek N E, et al. Environmental chemicals and thyroid function. Eur J Endocrinol, 2006, 154: 599-611

5 de Escobar G M, Obregón M J, del Rey F E. Maternal thyroid hormones early in pregnancy and fetal brain development. Best Pract Res Clin Endoc Metab, 2004, 18: 225-248

6 van der Plas S A, Lutkeschipholt I, Spenkelink B, et al. Effects of subchronic exposure to complex mixtures of dioxin-like and non-dioxin-like polyhalogenated aromatic compounds on thyroid hormone and vitamin A levels in female Sprague-Dawley rats. Toxicol Sci, 2001, 59: 92-100

7 Schriks M, Vrabie C M, Gutleb A C, et al. T-screen to quantify functional potentiating, antagonistic and thyroid hormone-like activities of poly halogenated aromatic hydrocarbons (PHAHs). Toxicol Vitro, 2006, 20: 490-498

8 Fowles J R, Fairbrother A, Baecher-Steppan L, et al. Immunologic and endocrine effects of the flame-retardant pentabromodiphenyl ether (DE-71) in C57BL/6J mice. Toxicology, 1994, 86: 49-61

9 World Health Organization. Chlorinated Naphthalenes. Concise International Chemical Assessment Document 34. Geneva, 2001

10 Kannan K, Imagawa T, Blankenship A L, et al. Isomer-specific analysis and toxic evaluation of polychlorinated naphthalenes in soil, sediment, and biota collected near the site of a former chlor-alkali plant. Environ Sci Technol, 1998, 32: 2507-2514

11 Hayward D. Identification of bioaccumulating polychlorinated naphthalenes and their toxicological significance. Environ Res, 1998, 76: $1-18$

12 Falandysz J. Polychlorinated naphthalenes: An environmental update.
Environ Pollut, 1998, 101: 77-90

13 Benfenati E, Mariani G, Fanelli R, et al. "De novo" synthesis of PCDD, PCDF, PCB, PCN and PAH in a pilot incinerator. Chemosphere, 1991, 22: 1045-1052

14 Yamashita N, Taniyasu S, Hanari N, et al. Polychlorinated naphthalene contamination of some recently manufactured industrial products and commercial goods in Japan. J Environ Sci Health Part A-Toxic/ Hazard Subst Environ Eng, 2003, 38: 1745-1759

15 Falandysz J. Chloronaphthalenes as food-chain contaminants: A review. Food Addit Contam, 2003, 20: 995-1014

16 United Nations Economic Commission for Europe. Technical Input for Reviewing Substances Under the 1998 Protocol on Persistent Organic Pollutants. Working Group on Strategies and Review, Thirtyeighth Session, Item 4 of the Provisional Agenda, 19-22 September 2006, Geneva

17 Blankenship A L, Kannan K, Villalobos S A, et al. Relative potencies of individual polychlorinated naphthalenes and Halowax mixtures to induce Ah receptor-mediated responses. Environ Sci Technol, 2000, 34: 3153-3158

18 Villeneuve D L, Kannan K, Khim J S, et al. Relative potencies of individual polychlorinated naphthalenes to induce dioxin-like responses in fish and mammalian in vitro bioassays. Arch Environ Contam Toxicol, 2000, 39: 273-281

19 Brucker-Davis F. Effects of environmental synthetic chemicals on thyroid function. Thyroid, 1998, 8: 827-856

20 Kitagawa H, Fujiki R, Yoshimura K, et al. The chromatin-remodeling complex WINAC targets a nuclear receptor to promoters and is impaired in Williams syndrome. Cell, 2003, 113: 905-917

21 Li J, Ma M, Wang Z J. A two-hybrid yeast assay to quantify the effects of xenobiotics on thyroid hormone-mediated gene expression. Environ Toxicol Chem, 2008, 27: 159-167

22 Nishikawa J-I, Saito K, GOTO J, et al. New screening methods for chemicals with hormonal activities using interaction of nuclear hormone receptor with coactivator. Toxicol Appl Pharmacol, 1999, 154: 76-83

23 Gaido K W, Leonard L S, Lovell S, et al. Evaluation of chemicals with endocrine modulating activity in a yeast-based steroid hormone receptor gene transcription assay. Toxicol Appl Pharmacol, 1997, 143: 205-212

24 Rehmann R K, Schramm K W, Kettrup A A. Applicability of a yeast oestrogen screen for the detection of oestrogen-like activities in environmental samples. Chemophere, 1999, 38: 3303-3312

25 Kucklick J, Helm P. Advances in the environmental analysis of polychlorinated naphthalenes and toxaphene. Anal Bioanal Chem, 2006, 386: 819-836

26 Domingo J L. Polychlorinated naphthalenes in animal aquatic species and human exposure through the diet: A review. J Chromatogr A, 2004, 1054: 327-334

27 Helm P A, Jantunen L M, Ridal J, et al. Spatial distribution of polychlorinated naphthalenes in air over the Great Lakes and air-water gas exchange in Lake Ontario. Environ Toxicol Chem, 2003, 22: 1937-1944

28 Harner T, Kylin H, Bidleman T F, et al. Polychlorinated naphthalenes and coplanar polychlorinated biphenyls in arctic air. Environ Sci Technol, 1998, 32: 3257-3265

29 Harner T, Lee R G M, Jones K C. Polychlorinated naphthalenes in the atmosphere of the United Kingdom. Environ Sci Technol, 2000, 34: 3137-3142

30 Norrgren L, Andersson T, Björk M. Liver morphology and cytochrome P450 activity in fry of rainbow trout after microinjection of lipid-soluble xenobiotics in the yolk-sac embryos. Aquat Toxicol, 1993, 26: 307-316

31 Henneman G, ed. Thyroid Hormone Metabolism. New York: Marcel Dekker, 1986

Open Access This article is distributed under the terms of the Creative Commons Attribution License which permits any use, distribution, and reproduction in any medium, provided the original author(s) and source are credited. 